\title{
Commentary: Maximum exposure
}

\author{
Connor P. McDonald, MD, and Dawn S. Hui, MD
}

Cardiovascular disease continues to account for a large proportion of morbidity and mortality across the globe, while the interest to pursue such a field among medical students continues to decline. The American Health Association estimates that by the year 2025, the demand for cardiothoracic (CT) surgeons may increase by $46 \%$ due to population growth and aging, with a projected $21 \%$ decrease in the supply of surgeons. ${ }^{1}$ In the United States, Coyan and colleagues $^{2}$ found that approximately $30 \%$ of first-year medical students expressed interest in cardiothoracic surgery (CTS); however, by their final year that number fell to less than $15 \%$. Axiaq and colleagues ${ }^{3}$ suggest that the overall number of total applicants for CTS in the United Kingdom continues to decline annually. This differs from the United States, where the National Resident Matching Program reports that the total number of applicants and positions among both CTS integrated and fellowship positions continues to increase. It should also be noted that the I-6 pathway continues to remain one of the most highly competitive matches, accounting for less than $1 \%$ of total residency positions among all residency programs and specialties. ${ }^{4}$

Although specialty training in the United Kingdom is similar in length to US I-6 training programs, the foundational UK training paradigm differs, with 5 to 6 years of undergraduate study, a 2-year Foundation program, and 2 years of core training. This pathway is considered a lengthy and challenging course as expanded on by Zakkar and colleagues ${ }^{5}$ and appears to be a significant deterrent, with more than $25 \%$ of trainees reporting it as a main reason for not pursuing the field. A concern that remains is the initial survey distribution to 17 of total 33 schools

\footnotetext{
From the Department of Cardiothoracic Surgery, Joe R. and Teresa Lozano Long School of Medicine, UT Health San Antonio, San Antonio, Tex.

Disclosures: The authors reported no conflicts of interest.

The Journal policy requires editors and reviewers to disclose conflicts of interest and to decline handling or reviewing manuscripts for which they may have a conflict of interest. The editors and reviewers of this article have no conflicts of interest.

Received for publication Sept 27, 2021; revisions received Sept 27, 2021; accepted for publication Sept 30, 2021; available ahead of print Oct 21, 2021.

Address for reprints: Dawn S. Hui, MD, 7703 Floyd Curl Dr, Suite 211L, San Antonio, TX 78229 (E-mail: huid@uthscsa.edu).

JTCVS Open 2021;8:518-9

2666-2736

Copyright (C) 2021 The Author(s). Published by Elsevier Inc. on behalf of The American Association for Thoracic Surgery. This is an open access article under the CC BY-NC-ND license (http://creativecommons.org/licenses/by-nc-nd/4.0/).

https://doi.org/10.1016/j.xjon.2021.09.042
}

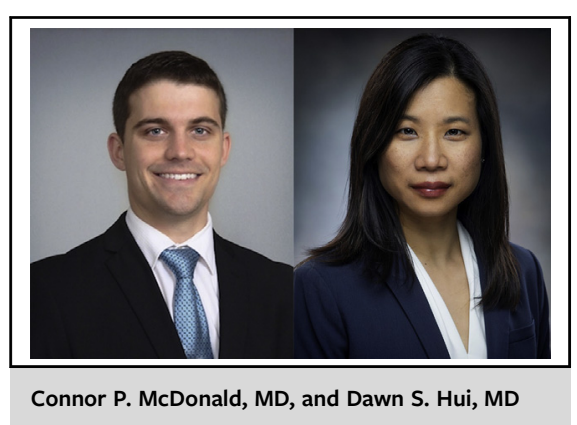

CENTRAL MESSAGE

Maximizing exposure and

engagement of medical students

remains the best avenue to

identify and develop the next

generation of CT surgeons.

in the United Kingdom, with a response rate of only approximately $3 \%(265 / 8730){ }^{6}$ This low response rate raises the question of response bias; however, one finds similar results in prior surveys such as by Gasparini and colleagues. ${ }^{6}$

Not surprisingly, this study once again highlights the importance of early exposure to the field. This remains one of the largest hurdles for recruitment, as authors found approximately $38 \%$ of respondents declaring no interest in the field as they progressed without any exposure through medical school. This complements the fact that most CT trainees have had some early exposure before or during medical school. Engagement remains a major opportunity for surgeons, because most CTS interest events during medical training were reportedly led by students. Leadership by CTS residents, fellows, and attendings may increase the quality of exposure and give students someone to connect to within the field itself. This remains especially important to shed light on important concerns, including "poor work-life balance, hostile environment, and an overall dying field." Programs such as the American Association for Thoracic Surgery Member for a Day hold great value in broadening interactive and mentoring opportunities for students. Financially, there are numerous organizational awards available to students and trainees, as outlined by Suarez-Pierre and Yang. ${ }^{7}$

Yet, we should proceed with reflection and prudence in these efforts. Maximizing interest indiscriminately should not be the sole goal; rather, we should strive to identify, mentor, and nurture the right candidates for the field. This includes avoidance of sugarcoating the specialty, which requires 
rigor and sacrifice including longer workdays, difficult material, commitment to patients and families, and longer training pathways. It involves being candid about the challenges of the discipline, now and in the future, to avoid attrition and burnout. It requires an investment in individuals who may ultimately decide not to pursue the field. As practitioners of a highly specialized domain, we are the only individuals who can paint a clear and complete picture of the challenges and rewards of this field for the next generation.

\section{References}

1. Grover A, Gorman K, Dall TM, Jonas R, Lytle B, Shemin R, et al. Shortage of cardiothoracic surgeons is likely by 2020. Circulation. 2009;120:488-94.
2. Coyan GN, Kilic A, Gleason TG, Schuchert MJ, Luketich JD, Okusanya O, et al Medical student perceptions of a career in CTS: results of an institutional survey. $J$ Thorac Cardiovasc Surg. 2020;159:1906-12.

3. Axiaq A, Visser R, Shirke M, Khashkhusha A, Zaidi S, Pillay R, et al. Understanding UK medical students' perspectives on a career in cardiothoracic surgery. $J$ Thorac Cardiovasc Surg. 2021:8:509-17.

4. National Resident Matching Program. Match Results Statistics, Thoracic Surgery Residency \& Fellowship. Available at: http://www.nrmp.org. Accessed September 11,2021

5. Zakkar M, Benedetto U, Angelini GD, Murphy G, Shah R, Jahangiri M, et al Cardiothoracic surgery training in the United Kingdom. J Thorac Cardiovasc Surg. 2019;157:1948-55.

6. Gasparini M, Jayakumar S, Ayton S, Nardini MN, Dunning JD. Medical student exposure to CTS in the United Kingdom. Interact Cardiovasc Thorac Surg. 2019;29:173-8

7. Suarez-Pierre A, Yang SC. Scholarships in cardiothoracic surgery-a guide for surgical trainees. J Thorac Cardiovasc Surg. 2021;161:1390-3. 